\title{
Socio-demographic Features of Mothers in Relation to Duration of Breastfeeding in Manipal Teaching Hospital, Pokhara, Nepal
}

\author{
Basnet $S,{ }^{1^{*}}$ Gauchan E, ${ }^{1}$ Malla $K,{ }^{1}$ Malla $T^{1}{ }^{1}$ Koirala DP, ${ }^{1}$ Rao KS, ${ }^{1}$ Sedai $Y,{ }^{1}$ Saha ${ }^{1}$ \\ ${ }^{1}$ Department of Pediatrics, Manipal Teaching Hospital, Pokhara, Nepal
}

\section{* Corresponding Author: \\ Dr. Sahisnuta Basnet, MBBS,MD \\ Department of Pediatrics \\ Manipal Teaching Hospital, Pokhara, Nepal \\ E-mail: sahisb@hotmail.com}

\section{Citation}

Basnet S, Gauchan E, Malla K, Malla T, Koirala DP, Rao KS, Sedai Y, Saha R. Socio-demographic features of mother in relation to duration of breast feeding in Manipal Teaching Hospital, Pokhara, Nepal. Nepal Journal of Medical Sciences. 2012; 1(1): 27-30.

\begin{abstract}
Background: It was noticed by the authors that the patients attending the Pediatrics Department were being breastfed for a longer duration than the recommended two years by the World Health Organization (WHO). This study was undertaken to see the exact duration of breastfeeding of the children who were being treated at the hospital.
\end{abstract}

Method: This was a prospective study carried out from April 2010 to March 2011 in 500 children who were treated at Manipal Teaching Hospital, Pokhara, Nepal. Other demographic features such as the mother's age, occupation, education, ethnicity and child's sex were also some of the factors which were studied to see if these factors influenced the duration of breastfeeding.

Results: Our study revealed that the median age of breastfeeding among the children studied was 43 months. Out of the 500 mothers who were interviewed 159 of them breastfed their child beyond the age of 60 months (5 years). In addition, we did not find any statistically significant gender discrimination with regards to the breastfeeding duration.

Conclusion: This study shows that the studied population has been breastfed for longer duration than the recommended guideline stipulated by the WHO. The duration of breastfeeding seen in this study is higher than shown in previous studies.

Keywords: Breastfeeding; extended breastfeeding; socio-demographic

\section{Background:}

B developing countries. Breastfeeding is practiced for longer periods in developing countries than in developed countries. World Health Organization (WHO) recommends infants to be breastfed to 24 months of life. ${ }^{1}$ We here at Manipal Teaching Hospital (MTH), Pokhara, Nepal, noticed that the children who were attending the out patient department and the in-patients seemed to be breastfeeding for longer durations than the recommended 24 months. So this study was undertaken to observe exactly how long mothers breastfed their child.

In addition to the duration of breastfeeding, this study will observe into several socio-demographic aspects of mother-child which have a candid effect on the duration of breastfeeding.

Methods:

This research was approved by the ethical committee of Manipal Teaching Hospital. The 500 data accumulated are from mother's who brought their child for treatment at MTH. This was a prospective study and data was collected between April 2010 and March 2011. Each individual's mother was asked a pre-structured questionnaire. We opted for querying rather than handing out a survey style sheet, because a lot of mother were believed to be illiterate and had no formal education, given the nature of Nepal's high illiteracy rate. Every mother-child that came for treatment were questioned, and skipped if they opted not to participate in this study. The mother's were formally educated and 
sought for their consent about the research prior to the questioning. The subjects were interviewed and information was accumulated.

The criteria of the questionnaire taken from the subjects were the age of the mother, education, occupation, duration of breastfeeding, ethnicity and the child's sex who were present during the interviewing process. This research will look into breastfeeding duration in correlation with mother's age, occupation, ethnicity, education and child's sex. Results were based on our statistical analysis which was done using EPI Info 3.5.2.

Results:

A cumulative of 500 mothers were interviewed. $52.6 \%$ of our subjects were in the age range of 26-35 years followed by $38.4 \%$ in the $18-25$ years age range. Out of the 500 subjects, 192 had some form of education between standard $5-10$, while 168 of them had less than standard 5 to no education and 160 subjects had over intermediate level education, out of which 62 had Bachelor's degree or above. 317 out of 500 of the mothers were housewives and out of the remaining 183, there were 97 farmers and 86 job holders. The frequencies of mothers age, education and occupation and exact breastfeeding duration is shown in Table 1 and 2 respectively.

Table 1 - Socio-demographic features of the mothers

\begin{tabular}{lcc}
\hline \multicolumn{1}{c}{ Variables } & Frequency & $\%$ \\
\hline Mother's Age & 0 & $0 \%$ \\
$<18$ Years & 192 & $38.4 \%$ \\
18-25 Years & 263 & $52.6 \%$ \\
26-35 Years & 43 & $8.6 \%$ \\
36-45 Years & 2 & $0.4 \%$ \\
$>45$ Years & & \\
Mother's Education & 99 & $19.8 \%$ \\
None & 69 & $13.8 \%$ \\
$<$ Standard 5 & 192 & $38.4 \%$ \\
Standard 5-10 & 78 & $15.6 \%$ \\
Intermediate & 62 & $12.4 \%$ \\
Bachelors + & & \\
Mother's Occupation & 317 & $63.4 \%$ \\
Housewife & 97 & $19.4 \%$ \\
Farmer & 86 & $17.2 \%$ \\
\hline Job Holder &
\end{tabular}

Table 2 - Exact breastfeeding duration and its frequency

\begin{tabular}{llc}
\hline Exact Breastfeeding Duration & Frequency & $\%$ \\
\hline 6 Months & 3 & $0.6 \%$ \\
9 Months & 1 & $0.2 \%$ \\
10 Months & 2 & $0.4 \%$ \\
1 Year & 6 & $1.2 \%$
\end{tabular}

\begin{tabular}{lll}
1 Year 6 Months & 12 & $2.4 \%$ \\
2 Years & 65 & $13 \%$ \\
2 Years 6 Months & 41 & $8.2 \%$ \\
3 Years & 117 & $23.4 \%$ \\
3 Years 5 Months & 1 & $0.2 \%$ \\
3 Years 6 Months & 7 & $1.4 \%$ \\
4 Years & 89 & $17.8 \%$ \\
4 Years 6 Months & 1 & $0.2 \%$ \\
5 Years & 136 & $27.2 \%$ \\
5 Years 5 Months & 1 & $0.2 \%$ \\
6 Years & 17 & $3.4 \%$ \\
7 Years & 1 & $0.2 \%$ \\
Total & 500 & $100 \%$ \\
\hline
\end{tabular}

Gender was based on the sex of the child brought for treatment while the questionnaires were being conducted. There were 293 male and 207 female. Gender didn't seem to affect the duration of breastfeeding (Table 3 ).

Table 3 - Duration of breastfeeding by gender

\begin{tabular}{lcccc}
\hline $\begin{array}{c}\text { Duration of } \\
\text { Breastfeeding }\end{array}$ & Male & \% & Female & \% \\
\hline$<1$ Yr & 2 & $0.7 \%$ & 1 & $0.5 \%$ \\
$1-2$ Yrs & 12 & $4.1 \%$ & 2 & $1 \%$ \\
$2-3$ Yrs & 51 & $17.4 \%$ & 35 & $16.9 \%$ \\
$3-4$ Yrs & 83 & $28.3 \%$ & 61 & $29.5 \%$ \\
$4-5 Y r s$ & 52 & $17.7 \%$ & 42 & $20.3 \%$ \\
$>5 Y r s$ & 93 & $31.7 \%$ & 66 & $31.9 \%$ \\
TOTAL & 293 & & 207 & \\
\hline
\end{tabular}

Brahmins dominated the list of ethnicity which was categorized in 12 groups, with 155 out of surveyed 500 followed by Dalits, Chhetri, Gurung, Magar, Newars, Tamang, Kirantis, Sherpa, Thakali, Muslims, and Others(Sah, Jalari, Dolma, Lama) meticulously in that order (Table 4).

Table 4 - Mean Duration of breastfeeding by ethnicity

\begin{tabular}{lcc}
\hline Ethnicity & $\begin{array}{c}\text { No. of } \\
\text { Infants }\end{array}$ & $\begin{array}{c}\text { Mean of Exact Duration } \\
\text { of Breastfeeding }\end{array}$ \\
\hline Brahmin & 155 & 43 Months \\
Chhetri & 68 & 41 Months \\
Newar & 31 & 45 Months \\
Gurung & 64 & 43 Months \\
Magar & 59 & 44 Months \\
Tamang & 7 & 43 Months \\
Kirantis & 5 & 30 Months \\
Sherpa & 3 & 53 Months \\
Thakali & 2 & 30 Months \\
Dalits & 87 & 45 Months \\
Muslim & 2 & 30 Months \\
Others & 17 & 41 Months \\
\hline
\end{tabular}




\section{Discussion:}

There has been very little research done on infants who are breastfed beyond the age of 24 months but available sources and information suggests that breastfeeding is a valuable source of nutrition and protection from diseases. ${ }^{2}$

The proportion of breastfeeding in developing countries to developed countries is several times higher. Through research, the average duration of breastfeeding is observed to be 3.7 months in Chile, 5.5 months in Colombia, 10.2 months in Phillipines, 14 months in Taiwan, 15.1 months in Egypt, 24 months in Senegal, ${ }^{3-10}$ and according to Department of Health Survey (DHS) Nepal 2006, 34 months in Nepal. ${ }^{11}$

Breast feeding practices in developing countries are prolonged and often appear longer than the recommended age of 24 months. The American Academy of Pediatrics has stipulated that "there is no upper limit to the duration of breastfeeding and no evidence of psychological or developmental harm from breastfeeding into the third year of life or longer". ${ }^{22}$ This type of breastfeeding practice, however is very indispensable for preponderance of infants in Nepal. Nepal's infants suffer from malnutrition due to high illiteracy among parents, poverty and rampant infectious diseases. ${ }^{13}$ Breast milk provides anti-infective properties, nutritional superiority to animal milk, low cost, free of contamination, contraceptive effects and many psychological benefits.

The tangibility of duration of breastfeeding is determined by scores of factors. Such factors are derisory of production of breast milk, diseases, illness or death of mother, occupational status, cultural and ethnical beliefs.

The mother's age, occupation, education, ethnicity and child's sex are some of the elements which have influenced in determining the pattern of duration of breastfeeding in urban areas of Pokhara, Nepal. One hundred and fifty-five of the mothers interviewed breastfed their child even after the age of 5. Correlating the breastfeeding duration with regards to mother's age, it can be concluded that mothers in the age range of 26-35 did this frequently; however no noteworthy relationship was seen regarding the mother's age and breastfeeding duration. With regards to mothers education with breastfeeding duration, $47.8 \%$ of mothers with less than standard 5 to no education breastfed their child beyond the age of 5 . Mothers who are in the agricultural occupation tend to breastfeed their children for longer according to our data showing that almost $90.7 \%$ have breastfed their child beyond the age of 36 months. This is the same finding as Huffman's article, where she mentions that job holders are likely to end breastfeeding earlier than other occupational group of women. ${ }^{14}$ This finding was possibly due to the fact that agricultural workers are in a closer proximity to their child as they take their child with them to the fields. Child's sex doesn't have much bearing on mother's attitude towards duration of breastfeeding. Ethnic groups which were referred to, based on designation by the United Sates Department of State, ${ }^{15}$ shows that the Dalits and Newaris tend to breastfeed their children the longest. Eighty two out of 87 Dalits breastfed their infant beyond the recommended 24 months whereas the Newaris had 28 out of 31 followed by Magars with 55 out of 59 . According to our data, the ethnicity which breastfed the least was the "Others" category which included ethnicity such as Sah, Jalari, Dolma, Lama. These data runs parallel to the fact that the Newari community adheres to principals that mother's milk is sacred and believes in repayment of it during wedding ceremony by providing a gallon of milk with molasses and cardamom. In Magar community, there is a system where the bride's mother is given one and half rupees during wedding ceremony to signify separation of daughter from mothers lap. ${ }^{16}$ These cultural and ethnic beliefs complements our data where the Newar and Magar community are some of the top ethnic groups whose breastfeeding durability is the longest. Newar and Magar community have average breastfeeding duration of 45 and 44 months respectively. According to our study, the Sherpa community hogged the highest mean on longevity of breastfeeding, but since we only had 3 subjects in that group, we have drawn a conclusion that it cannot be satisfactorily compared with other groups, and a conclusive hypothesis cannot be depicted based on the insufficient data we acquired. Correlating exact breastfeeding duration with ethnic groups, it can be concluded that most groups do tend to breastfeed till the 43 months period. Brahmins, Gurungs and Tamangs had a mean of 43 months, Chhetris and "Others" origins falling outside our categorized ethnic groups had a mean of 41 months, whereas the Kirantis, Thakalis and Muslims had the least averages at 30,30 and 27 months respectively. The fact that Kirantis, Thakalis and Muslims average vary incredibly compared to other ethnic group might be because of the inadequate number of subjects from these groups (Table 6).

WHO suggests children to be breastfed till 24 months of life. In our study, it clearly shows that $155(33 \%)$ of mothers breastfed their children atleast till the age of 5. In Nepal's cultural belief, it is said that mothers milk is an extremely pure food and that separating the child from its mothers milk can lead to vulnerability to infections and diseases. This explains the high number on prolonged breastfeeding among the women surveyed.

According to DHS Nepal 2006, male children were breastfed for longer periods than female children. ${ }^{11}$ According to Das $\mathrm{N}$, the reason behind this is because male are considered more dominant than female, male outnumber female population wise as well as male are prominently found in the 
work force than female, and also parents tend to keep trying for a child until a son is born. ${ }^{17}$ Although what Das $\mathrm{N}$ stated in his article is very similar to the pattern of male and female children breastfeeding in Nepal, this information does not run parallel with our study where it showed almost equal proportion on breastfeeding practice according to child's sex. Two hundred and twenty eight out of 293 of the male infants were breastfed beyond the age of 36 months whereas 168 of 207 for female which proportionally is almost similar.

The mean of frequency of breastfeeding duration in Nepal is 30 months and median is 34 months. ${ }^{11}$ Our study shows a significant different and higher mean of 43 months and median of 42 months. The reason for this might be because of selective regional data sought rather than on all regions of Nepal.

\section{Conclusion:}

This study focuses on breastfeeding practices in Pokhara, Nepal. Every child included in this study was breastfed. Comparing breastfeeding duration with socio-demographic factors, it can be concluded that mothers are breastfeeding their children for an elongated period of time, in some cases upto 7 years when the recommended period is 24 months. The WHO maintains in its guidelines on the subject that exclusive breastfeeding is recommended up to six months of age, with continued breastfeeding along with appropriate complementary foods up to two years of age or beyond, but what about extended breastfeeding, from the age of two and beyond? Physiologically, no research yet exists to suggest that breastfeeding for longer than two years is significantly beneficial. The WHO has stated: "We don't know. There is no evidence either way." Therefore, we the authors recommend that further studies be carried out to see the tangible effects of extended breastfeeding in children over 2 years of age.

\section{Acknowledgement:}

The author would like to thank Mrs. Aishwarya KC, the interns from Manipal Hospital who were involved in interviewing the subjects and the mother-children in partaking in this study and others who have been directly and indirectly involved.

\section{References:}

1. World Health Organization, Breastfeeding c2011 [2010 May 2010, cited 2010 Dec 20]. Available from www.who.int/topics/breastfeeding/en

2. Dewey KG. Nutrition, Growth, and Complementary Feeding of the Breastfed Infant. Pediatr Clin North Am 2001;48:87-104.

3. Perez A, Potrer R, Masnick GS. Timing and sequence of resuming ovulation and menstruation after childbirth. Pop Studies 1971;25:491-6.
4. Obserndorfer L, Mejia W. Statistical analysis of the duration of breastfeeding (a study of 200 mothers of Antioquia Province, Colombia). J Trop Pediat 1968;4:27-32.

5. Osteria T. Lactation and postpartum amenorrhea in a rural community. Acta Med Phillippina. 1973;9:144-9.

6. Jain K, Hsu C, Freedman R, et al. Demographic aspects of lactation and postpartum amenorrhea. Demography 1970;7:255-71

7. Kamal I, Hefnawi F, Ghoneim M, et al. Clinical, biochemical, and experimental studies on lactation. Am J Obstet Gynecol 1969;105:314-23.

8. Bonte M, Van Balen H. Prolonged lactation and family planning in Rwanda. J BioSocial Sci 1969;1:97-100.

9. Cantrelle P, Leridon H. Breastfeeding, mortality in childhood and fertility in a rural zone of Senegal. Pop Studies 1971;25:505-33.

10. Singarimbun M, Manning C. Breastfeeding, amenorrhea, and abstinence in a Javanese village: a case study of Mojolama. Studies Family Planning $1976 ; 7: 175-9$.

11. Ministry of Health and Population (MOHP) [Nepal], New ERA, and Macro International Inc. 2007. Nepal Demographic and Health Survey 2006. Kathmandu, Nepal: Ministry of Health and Population, New ERA, and Macro International Inc: 173-198, 2006.

12. American Academy of Pediatrics Section on Breastfeeding. Breastfeeding and the Use of Human Milk. Pediatrics 2005;115:496-50.

13. Rai SK, Hirai K, Abe A, et al. Infectious Diseases and Malnutrition Status in Nepal: an Overview. Mal J Nutr 2002;8:191-200.

14. Huffman S, Chawdhury A, Chakraborty J, et al. Breastfeeding Patterns in Rural Bangladesh. Am J Clin Nutr 1980;33:144-54.

15. United States Department of State. Washington, DC. Background Note: Nepal. c2011 [2010 April 20; cited 2011 Jan 2010]. Available from: http://www.state. gov/r/pa/ei/bgn/5283.htm

16. Paneru S. Breast Feeding in Nepal: Religious and Culture Beliefs. CNAS Journal 1981;3:43-52.

17. Das N. Sex Preference and Fertility Behavior: A Study of Recent Indian Data. Demography 1987;24:517-30. 